$16 \mid 2020$

Les marges créatrices : intellectuel.le.s afrodescendant.e.s et indigènes auX Amériques, XIX-XXe siècle

\title{
Gonçalves Dias, Machado de Assis e Racionais Mc's: a invenção do centro
}

Gonçalves Dias, Machado de Assis and Racionais Mc's: the invention of the center.

Gonçalves Dias, Machado de Assis et Racionais Mc's: l'invention du centre.

\section{Valmir Luis Saldanha da Silva}

\section{OpenEdition}

\section{Journals}

Edição electrónica

URL: http://journals.openedition.org/ideas/8842

DOI: $10.4000 /$ ideas.8842

ISSN: 1950-5701

\section{Editora}

Institut des Amériques

\section{Refêrencia eletrónica}

Valmir Luis Saldanha da Silva, « Gonçalves Dias, Machado de Assis e Racionais Mc's: a invenção do centro », IdeAs [Online], 16 | 2020, posto online no dia 01 outubro 2021, consultado o 22 outubro 2020. URL : http://journals.openedition.org/ideas/8842 ; DOI : https://doi.org/10.4000/ideas.8842

Este documento foi criado de forma automática no dia 22 outubro 2020.

\section{$\Theta \Theta \Theta$}

IdeAs - Idées d'Amériques est mis à disposition selon les termes de la licence Creative Commons Attribution - Pas d'Utilisation Commerciale - Pas de Modification 4.0 International. 


\title{
Gonçalves Dias, Machado de Assis e Racionais Mc's: a invenção do centro
}

\author{
Gonçalves Dias, Machado de Assis and Racionais Mc's: the invention of the \\ center. \\ Gonçalves Dias, Machado de Assis et Racionais Mc's: l'invention du centre.
}

Valmir Luis Saldanha da Silva

\section{Introdução}

1 Neste artigo, buscamos tratar do papel que a estrutura social e histórica do Brasil nos séculos XIX e xx desempenhou na situação de intelectuais negros e mestiços brasileiros. Isso tanto em relação ao espaço social autorizado institucionalmente, como é o caso de Gonçalves Dias (1823-1864) e Machado de Assis (1839-1908), quanto à tomada dos espaços sociais por meio de um discurso contundente, como o fizeram os integrantes do grupo musical Racionais Mc's, fundado em 1988.

2 Sabendo que a definição sobre o que são valores marginais e centrais, dentro de uma cultura, é extremamente complexa, nossa intenção é contribuir para esse debate por meio de uma análise de produções estéticas dos intelectuais supracitados em relação ao ponto de vista ético e moral prevalente no contexto da recepção primeira de suas obras e no lastro histórico deixado. Isso porque os caracteres histórico-sociais são um dos elementos responsáveis tanto por impulsionar quanto por silenciar um ou outro tema artístico, um ou outro autor, um ou outro estilo e declará-los como sendo oficiais ou marginalizados.

\section{Gonçalves Dias}

3 A vida e a obra de Antônio Gonçalves Dias já são bastante conhecidas por quem tem interesse na formação da identidade nacional brasileira. O poeta da Canção do exílio, mestiço, "filho de um comerciante português e de uma mestiça, talvez cafuza, pois o 
poeta se dizia descendente das três raças que formaram a etnia brasileira" (Bosi A., 2006 : 104), foi o maior expoente da estética romântica nacionalista e indianista. Para Bosi, por exemplo, “A lírica de Gonçalves Dias singulariza-se no conjunto da poesia romântica brasileira como a mais literária, isto é, a que melhor exprimiu o caráter mediador entre os polos da expressão e da construção" (Bosi A., 2006 : 104). Isso porque a obra do poeta maranhense vinha na esteira da independência política, de 1822, em que "a literatura foi considerada parte dum esforço construtivo mais amplo, [...] este senso de dever patriótico, que levava os escritores não apenas a cantar a sua terra, mas a considerar as suas obras como contribuição ao progresso" (Candido A., $1981: 10$ ).

4 Como se vê, esse nacionalismo idealizante envolvia a obra dos intelectuais da época. Também porque o Brasil "logo depois da independência precisava encontrar um passado independente da história colonial, pois esta era comum com Portugal. E Portugal era, na época, o inimigo, a nacionalidade de que a brasileira precisava distinguir-se" (Leite D. M., $2007: 225$ ). Nesse sentido, a natureza tropical brasileira e principalmente o indianismo surgem como o principal eixo de sustentação de uma identidade que precisava ser inventada.

O caráter oficial dessa invenção repousava, de um lado, na aceitação do programa de Almeida Garrett, que em 1826 escreve o ensaio História abreviada da língua e poesia portuguesa e lamenta que "a educação europeia" atrapalhe o olhar mais original para "as majestosas e novas cenas da natureza" (Leite D.M., 2007 : 222). De outro lado, repousava principalmente na aceitação do programa de Ferdinand Denis, que escreve o Résumé de l'histoire littéraire du Portugal, suivi du Résumé de l'histoire littéraire du Brésil, em 1826. Em seu texto, Denis analisa as letras de Portugal e do Brasil para o público francês de modo separado, uma vez que a nação brasileira se constituía como ser autônomo. Para o pensador francês, a raça e o ambiente geográfico deveriam ser materiais essenciais da literatura "americana", já que:

A América deve ser livre tanto na poesia como no seu governo. [...]

Se os poetas dessas regiões fitarem a natureza, se se penetrarem da grandeza que ela oferece, dentro de poucos anos serão como nós, talvez nossos mestres. [...]

Mas [o poeta] não esqueça também os erros do passado [...]; lamente as nações exterminadas, excite uma piedade tardia, mas favorável aos restos das tribos indígenas; e que este povo exilado, diferente na cor e nos costumes, não seja nunca esquecido pelos cantos do poeta. [...]

Quer descenda do europeu, quer esteja ligado ao negro ou ao primitivo habitante da América, o brasileiro tem disposições naturais para receber impressões profundas.

(Denis F., 1978 : 36-38)

6 Pouco depois, a entrada do Imperador e mecenas D. Pedro II no Instituto Histórico e Geográfico Brasileiro (IHGB), criado em 1838, proporcionou que a estética romântica fosse transformada em "projeto oficial, em verdadeiro nacionalismo" e, justamente por isso, devesse "inventariar o que deveriam ser as 'originalidades locais"” (Schwarcz L., 1998:131). Além do Imperador, outros importantes nomes da classe intelectual como Gonçalves de Magalhães, Manuel de Araújo Porto-Alegre, Joaquim Norberto de Sousa Silva, Joaquim Manuel de Macedo e Francisco Adolfo Varnhagen faziam parte do IHGB, ou melhor, como bem observa Wilton Marques (2010:21), "entraram para a burocracia imperial por portas abertas pela mão seletiva do favor". Sendo o favor "nossa mediação quase universal" (Schwarz R., 2000:16), após o sucesso dos livros Primeiros cantos (1847) e Segundos cantos (1848) "Gonçalves Dias, apoiado notadamente no sucesso de suas 
'poesias americanas', foi sendo, aos poucos, incorporado a esse seleto grupo de escritores vinculados ao próprio Imperador." (Marques W., 2010:45).

7 Assim, mesmo acreditando "ingenuamente ou não, ser reconhecido, sobretudo, por seus méritos literários e intelectuais” (Marques W., 2010:44), Gonçalves Dias não conseguiu - ou talvez nem fosse possível - escapar do mecanismo do favor e em março de 1849 foi nomeado professor de Latim e de História do Brasil no Colégio Pedro II. Analisando documentos históricos e biográficos sobre Dias, Marques afirma que "sua nomeação aponta mesmo para o fato de o poeta, sócio do IHGB há quase um ano e meio, ter conseguido tal cargo por ter, na verdade, se aproximado do 'seleto grupo' de escritores vinculados ao próprio Imperador.” (Marques W., 2010:49). Ora, o que todos esses dados revelam é que, de fato, Antônio Gonçalves Dias demonstrava enormes qualidades literárias, bem ao gosto do que o espírito da época pedia, mas por não ter vindo de família abastada, sua estabilidade só seria conseguida através de apadrinhamentos, pois "seja do próprio Imperador, seja de algum ministro, Gonçalves Dias sabia plenamente que a dependência era um mal necessário a sua sobrevivência." (Marques W., 2010:56).

\section{0 poeta na contramão}

8 Como se vê, o fato de ser mestiço não foi, nesse sentido, um problema para que Gonçalves Dias atingisse os mais altos patamares dentro da burocracia do Segundo Reinado brasileiro, já que seu talento de poeta e principalmente a boa vontade com que ele foi recebido por pessoas importantes dentro do Império foram determinantes para que ele se estabelecesse. $O$ mesmo, no entanto, não se poderá dizer em relação à vida privada de Dias, já que "o poeta viu recusado um pedido seu de casamento; ao que se sabe, não a jovem Ana Amélia, mas a sua família opôs-se por preconceito de cor" (Bosi A., 2006:104). Essa relação conflituosa entre os elementos oficiais e externos, que colocam o poeta no centro da cultura brasileira, e os particulares e internos, que não dissimulam os preconceitos raciais nas relações sociais brasileiras, ressoará em uma obra sobre a qual a crítica literária manteve silêncio durante muito tempo e, só agora, começa a recuperar: a Meditação.

9 Essa obra inacabada constitui-se de três capítulos denominados Fragmentos, escritos entre 1845 e 1846 e publicados separadamente na revista Guanabara em 1850, em que um jovem e um velho dialogam sobre o destino do Brasil, suas "raças, os escravos, os índios à margem do progresso, a iniquidade da vida política" (Candido A., 1981:52). A crítica mais recente questionará justamente o fato de que, mesmo os Fragmentos tendo sido publicados ao longo de 1850, em um periódico que desempenhava a função de um "quase 'diário oficial' do romantismo local", "até onde se conseguiu averiguar, não foi encontrado nos jornais ou revistas da época nenhum comentário crítico a essa obra." (Marques W., 2010:263). Assim, a coragem de contrariar toda a estrutura social brasileira da época e publicar sua Meditação faz de Gonçalves Dias um poeta na contramão:

Contrariando uma possível atitude passiva, num momento em que um inevitável silêncio de resignação frente às mazelas sociais do país talvez fosse a opção mais fácil entre os literatos que, em sua grande maioria, também eram funcionários públicos, Gonçalves Dias, então professor de latim e de história do Brasil no Imperial Colégio Pedro II, não apenas insistiu em tornar pública essa obra de juventude [Meditação], que apesar de inacabada, cristalizava sua visão crítica sobre 
o país, como também, para isso, escolheu um periódico emblemático para a própria consolidação do Romantismo brasileiro.

(Marques W., 2010:110).

10 Assim sendo, mesmo tendo um imenso potencial desagregador do centro ético-estético do reinado de Pedro II (ou talvez por isso mesmo), a crítica da época resolveu silenciar sobre a publicação repleta de denúncias que o poeta da idealização da pátria e dos indígenas trazia ao público. Como exemplo da força do texto do poeta da Canção do exilio, leiamos um trecho do primeiro fragmento de Meditação, em que o jovem interlocutor, magicamente, pode realmente ver a organização da sociedade brasileira:

Então o velho estendendo a mão descarnada e macilenta tocou as minhas pálpebras, que cintilaram como sentindo o contato de um corpo eletrizado. [...]

E eu levei os meus olhos de norte a sul, do ocaso ao nascer do sol, 'té onde eles alcançavam, e respondi:

[...] vejo milhares de homens de fisionomias discordes, de cor vária e de caracteres diferentes.

E esses homens formam círculos concêntricos, como os que forma a pedra, caindo no meio das águas plácidas de um lago.

E os que formam os círculos externos têm maneiras submissas e respeitosas, são de cor preta; - e os outros, que são como um punhado de homens, formando o centro de todos os círculos, têm maneiras senhoris e arrogantes, e são de cor branca.

E os homens de cor preta têm as mãos presas em longas correntes de ferro, cujos anéis vão de uns a outros, eternos, como a maldição que passa de pais a filhos ${ }^{1}$.

(Dias A. G., 1850:102)

11 A imagem não é difícil de ser decifrada. Os homens do centro são de cor branca, "senhoris e arrogantes", e têm o Brasil em suas mãos de ferro, com as quais açoitam e subjugam os "submissos e respeitosos" homens da periferia, de cor preta, cujas mãos não podem libertar-se da "eterna maldição" de terem nascido pretos e, por isso, serem escravizados. O sentimento de nulidade dos escravos é acentuado em seguida quando o jovem narrador da Meditação, ainda em estado de ascese, vê

quando um mancebo, imberbe, saindo dentre os homens de cor branca, açoitou as faces de outro de cor preta com o reverso de sua mão esquerda.

E o ofendido, velho e curvado sob o peso dos anos, cruzou os braços, musculosos apesar da velhice, e deixou pender a cabeça sobre o peito.

E após um instante de silêncio profundo, arrojou-se aos pés de um ancião de cor branca, clamando justiça com voz abafada.

E um dentre estes, na flor da idade, ergueu-se iroso entre os dois anciãos de cabelos brancos e lançou por terra o injuriado, que pedia justiça.

(Dias A. G., 1850:103)

12 Gonçalves Dias, como é notório, ao descrever as tensas relações sociais entre brancos e pretos no Brasil do século XIX demonstra o lugar que cada um deles ocupa na estrutura social brasileira da época: os brancos no centro e os pretos na periferia. Tendo sido publicado, em 1850, ainda que silenciado pelos críticos, em momento no qual as elites brasileiras invisibilizavam os negros, o trabalho do mestiço Gonçalves Dias tem o mérito de trazer para o centro do debate a questão da escravidão. No entanto, há ainda um mérito maior, que é o de demonstrar simbolicamente a ilusão de desenvolvimento sobre a qual o Brasil se apoiava, pois eram os escravizados que sustentavam a mola político-econômico-social do Império:

Por isto o estrangeiro que chega a algum porto do vasto Império, consulta de novo a sua derrota, e observa atentamente os astros, porque julga que um vento inimigo o levou às costas d'África.

E conhece, por fim, que está no Brasil, a terra da liberdade, a terra ataviada de 
primores, e esclarecida por um céu estrelado e magnífico.

Mas grande parte da sua população é escrava; mas a sua riqueza consiste nos escravos; mas o sorriso, o deleite do seu comerciante, do seu agrícola e o alimento de todos os seus habitantes é comprado à custa do sangue e do suor do escravo.

E nos lábios do estrangeiro que aporta ao Brasil, desponta um sorriso irônico e despeitoso; e ele diz consigo que a terra da escravidão não poderá durar muito; porque é crente, e sabe que os homens são feitos do mesmo barro, sujeitos às mesmas dores e às mesmas necessidades.

(Ibid., p. 104)

13 O que Gonçalves Dias, mesmo estando em uma posição privilegiada na burocracia imperial, demonstra com seu texto é que a ilusão romântica da "terra da liberdade e dos primores" não iria durar muito se continuasse sendo guiada pelo sangue e pelo suor dos escravizados.

\section{Machado de Assis}

Após passarmos pela Meditação de Gonçalves Dias, de 1850, ano da promulgação da lei Eusébio de Queiroz que extinguia o tráfico negreiro, mas não abolia a escravidão no Brasil, avancemos um pouco e observemos Joaquim Maria Machado de Assis, "filho de um pintor mulato e de uma lavadeira açoriana", cuja ficção é considerada "o ponto mais alto e mais equilibrado da prosa realista brasileira" (Bosi A., 2006:174). A escola realista no Brasil sucede à romântica, quase sempre querendo colocar-se como oposta à anterior, ou seja, afastando-se do nacionalismo ufanista, da benévola mãe-natureza e da idealização do amor. A partir de 1870, então, modificam-se as formas de interpretar a vida brasileira e Machado mostra-se como o autor que melhor consegue reunir as distintas perspectivas em sua obra.

Essa harmonia machadiana vem, em geral, do fato desse autor não deixar seus textos serem empolgados pelas teorias cientificistas que, por exemplo, o recifense Silvio Romero acreditava serem guias máximas de conduta e moral. Dessa forma, enquanto Romero destacava entre seus mestres Taine, Comte, Spencer, Darwin e Gobineau, autores que, cada um a seu modo, "aceitavam uma evolução linear da história humana, cujo ponto final seria a sociedade europeia do século XIX" (Leite D. M., 2007:241), Machado, muito mais cético em relação às teorias evolucionistas, principalmente a partir das Memórias póstumas de Brás Cubas (1881), rejeitava rótulos e soluções fáceis e, muito por isso, fazia de seus textos um painel cheio de pessimismo e humor em relação à sociedade do século XIX.

Não por acaso, Earl E. Fitz (2016:23) expõe que, do ponto de vista formal do romance moderno, "vejo Machado de Assis como o elo que faltava entre Flaubert e Proust, o escritor cuja melhor obra nos presenteia com a mais profunda e mais imaginativa transição, na tradição ocidental, do Realismo para o Modernismo". Em tempo, "O maior literato negro surgido até o presente" (Bloom H., 2003:687), aquele que revolucionou a literatura brasileira e transformou-se em um "mestre" da periferia ocidental (Sontag S., 1990; Schwarz R., 2000), na verdade, muitas vezes foi visto pela crítica como um absenteísta em relação à premente questão da escravidão no Brasil do século xix. Por absenteísta devemos compreender alguém que se absteve, isto é, que não tomou partido em uma determinada disputa. No entanto, ainda que recorrente, essa leitura nos parece equivocada. 
17 Fitz, uma vez mais, discutindo a recepção da obra machadiana nos EUA nos anos 1950 e 1960, questionará por que Machado de Assis “não foi reconhecido como um escritor que questionava a moral de uma cultura baseada na escravidão, na opressão e na busca de satisfação de desejos e interesses individuais" e, mais ainda, "Por que não foi lido nos Estados Unidos como um autor que tinha algo importante a dizer sobre relações raciais [?]" (Fitz E., 2012:40). A dúvida de Fitz é a mesma que temos, no entanto não só em relação à recepção de Machado nos Estados Unidos, mas também no Brasil, na Europa e no resto do mundo: seria mesmo Machado um absenteísta?

\section{Um mestre na periferia}

18 No dia 28 de setembro do ano de 1871 foi promulgada, no Brasil, a Lei do Ventre Livre, que decidia que os filhos de mulher escrava nascidos a partir daquela data seriam considerados livres e teriam de ser tratados e criados pelos senhores das mães-escravas até a idade de oito anos. Nesse sentido, ainda que controversa, essa lei significou um importante passo em direção à emancipação dos escravizados. Já aqui podemos ver o posicionamento crítico de Machado de Assis, pois em carta de 30 de setembro de 1876 endereçada ao visconde do Rio Branco, que tinha sido um dos mais importantes nomes nos debates em favor da Lei de 1871 - o escritor afirma:

Fui apenas um eco da opinião contemporânea e ainda mais das gerações vindouras. Quando um alto espírito, lançando os olhos por cima da cabeça de seu século, presta à terra de que é filho, um serviço tão assinalado como o que Vossa Excelência fez ao Brasil com a lei que iniciou e defendeu, não se pertence mais, é patrimônio comum, e recordar-lhe a glória equivale a participar dela.

Foi o que fiz, e tal é o meu quinhão no grande ato de Vossa Excelência.

(Assis M. de, 2009:123-124)

19 Por esse trecho de carta, pouco restaria para quem duvida do lugar de Machado de Assis nas lutas contra a escravidão. Isso porque ser um "eco da opinião contemporânea" é, por certo, posicionar-se ao lado dos defensores da liberdade no momento presente e para as "gerações vindouras". Contudo, a humanização dos negros na obra de Machado de Assis não se limitou a uma carta. Veja-se, por exemplo, a mudança de tom que ocorre no tratamento da mesma temática - a união impossível de uma escravizada com seu senhor - em duas obras distintas: Mariana, conto publicado em janeiro de 1871 no Jornal das Familias, e Sabina, poema que consta do livro de poesias Americanas, publicado em 1875.

20 No conto Mariana, a escrava doméstica que dá nome ao texto apaixona-se por seu senhor, porém, impossibilitada de viver o amor que deseja, suicida-se. Neste conto, não se vê apenas a escrava, mas o ser humano que consciente da alteridade que a limita, decide com autonomia pelo próprio fim. Ou seja, mesmo que se suicide, há uma concepção humanizada no texto: a de que é Mariana a responsável pela escolha do próprio destino. No poema Sabina, retorna a temática da negra escravizada que se apaixona pelo senhor. Quando descobre que está grávida e toma consciência de que ela tinha sido para o senhor apenas um objeto sexual, Sabina também pensa em suicídio, entretanto "opta pela vida do filho. A desistência do suicídio demonstra a consciência da cativa em relação à lei do Ventre Livre, visto que esta lei é anterior à publicação do poema" (Bruno A. L. P, 2012:89). 
do poema é singular: o eu lírico descreve o volúvel desejo do moço Otávio e seu casamento com uma gentil donzela de quinze anos. Como a cerimônia é presenciada por Sabina, ela pensa em suicídio, mas "Vence o instinto de mãe. Erma e calada/ Ali ficou. Viu-a jazer a lua/ Largo espaço da noite ao pé das águas/ E ouviu-lhe o vento os trêmulos suspiros/ Nenhum deles, contudo, o disse à aurora" (Assis M., 1994:47). O nascer do sol, a aurora, é metaforicamente a possibilidade de constituir uma vida melhor para si e, principalmente, para a criança que Sabina carregava no ventre. Assim, a escuridão da noite embalou suas dores, mas o dia que se anunciava (a Lei do Ventre Livre, por certo) trazia a esperança de que a vida ainda valeria a pena, mesmo para aqueles que, como o filho que ela trazia no ventre, tivessem a marca da escravidão impregnada no corpo e no passado.

Impossível ficar indiferente à sutil discussão que Machado de Assis promove. Em outro momento, a questão ganha mais força ainda. É, por exemplo, o que ocorre na crônica de número 29, publicada na Gazeta de Holanda no dia 27 de setembro de 1887. Nessa crônica escrita em redondilhas, Machado aborda as discussões que vinham tomando o parlamento brasileiro da época, em que advogados "nos deram// Uma questão - se, fundado/ Este regime presente,/ Pode ser considerado/ O escravo inda escravo ou gente." (Assis M., 1937:64-65). O ponto de vista assumido na crônica é bastante explícito: na sociedade brasileira da época, aqueles que viviam como escravos tinham negado o direito de serem considerados humanos. Vale lembrar que pouco depois, em 13 de maio de 1888, a princesa Isabel sancionaria a Lei nº 3.353 - Lei Áurea -, que concederia, ao menos em tese, liberdade total aos escravizados no Brasil.

Ora, a crítica machadiana aqui é fina, mas corrosiva, já que expõe as disputas que os homens das leis - no texto, representados pelo "Instituto" - travam entre si, mas que pouco mudam a vida dos pretos que sofriam - e ainda sofrem - a realidade de fato. $́$ é isso o que se lê a seguir, na mesma crônica:

$\mathrm{Eu}$, que suponho acertado,

Sempre nos casos como esses,

Indagar do interessado

Onde acha os seus interesses,

Chamei cá do meu poleiro

Um preto que ia passando,

Carregando um tabuleiro,

Carregando e apregoando.

E disse-lhe: "Pai Silvério,

Guarda as alfaces e as couves;

Tenho negócio mais sério,

Quero que m'o expliques. Ouves?"

Contei-lhe em palavras lisas,

Quais as teses do Instituto,

Opiniões e divisas.

Que há de responder-me o bruto?

- "Meu senhor, eu, entra ano,

Sai ano, trabalho nisto;

Há muito senhor humano,

Mas o meu é nunca visto.

"Pancada, quando não vendo,

Pancada que dói, que arde;

Se vendo o que ando vendendo,

Pancada, por chegar tarde. 


\begin{abstract}
"Dia santo nem domingo
Não tenho. Comida pouca:

Pires de feijão, e um pingo

De café, que molha a boca.

"Por isso, digo ao perfeito

Instituto, grande e bravo:

Tu falou muito direito,

Tu tá livre, eu fico escravo."

(Assis M., 1937 : 65-66)
\end{abstract}

Além da crítica social que essa crônica encerra, um aspecto formal deve ser levado em consideração. Ao fazer com que o narrador da crônica abra espaço para que Pai Silvério fale por si, ele o humaniza e, mais do que isso, permite que o olhar dos leitores seja conduzido não por aqueles que costumeiramente já o fazem, mas pelo marginalizado. 0 que Machado de Assis faz em seu texto é, portanto, atualizar as noções de central e periférico. $\mathrm{O}$ centro, nesse caso, corresponde aos campos dominantes da história social a que o narrador da crônica pertence. $O$ descentramento, por sua vez, compreende-se como um conjunto de forças voltadas contra a exclusão social, política e econômica em que a voz de Pai Silvério liga-se discursivamente à voz do narrador. Em outras palavras, a variação da modalidade narrativa de primeira pessoa aqui corresponde a uma relação de aproximação com as ideias centrais da cultura e, em seguida, a uma subversão desse centro, destruindo as bases ideológicas sobre as quais ele se sustenta e, ao contrário do que se poderia supor, revelando apenas a ruína histórico-social existente.

\title{
Racionais Mc's
}

Se Gonçalves Dias e Machado de Assis, negros ambos, em alguns momentos de suas obras atuaram no sentido de denunciar a situação dos escravizados no Brasil do século XIX, eles o fizeram a partir de um ponto de vista central. Isso porque, ainda que houvesse crítica em seus textos, tanto um quanto outro estavam protegidos pela estrutura burocrática do Império Brasileiro, sendo funcionários públicos respeitados. Não nos parece, é verdade, que houvesse muitas outras maneiras de, sendo homens livres, sobreviverem sem os favores da elite, já que a estrutura social brasileira da época dividia-se entre: a) a elite, que figurava no topo da pirâmide, b) a massa de escravos que sustentava a nação, sendo o "pão de que vos alimentais, as telas que vestis, o vosso pensamento cotidiano, e o vosso braço incansável" (Dias A. G., 1850:105) e c) os homens livres que, apesar de serem livres da escravidão, estavam presos à necessidade de agradar às elites para poderem sobreviver (Schwarz R., 2000).

Por outro lado, o grupo de rap Racionais Mc's formado no fim dos anos 1980 por Edivaldo Pereira Alves (Edi Rock), Kleber Geraldo Lelis Simões (KL Jay), Pedro Paulo Soares Pereira (Mano Brown) e Paulo Eduardo Salvador (Ice Blue) nas periferias da cidade de São Paulo, representa justamente uma inversão do que Dias e Machado haviam começado. Com os Racionais, a inversão centro-periferia completa-se e os versos das letras de rap marcam o enfrentamento que os sujeitos negros assumem diante da exclusão a que foram relegados. Apesar de ser explicitamente contraditório, o que se viu após a abolição da escravatura não foi a sociabilização e a integração dos negros na cidadania brasileira, mas justamente o contrário. 0 motivo, para citar o pensamento de André Rebouças, foi que "a liberdade que emergiria do processo de abolição da escravidão somente seria efetiva se referida a um fundamento material - a 
propriedade de terra - e a uma dimensão coletiva" (Carvalho M. A. R., 2009:57). Todavia, o Estado brasileiro atuou efetivamente contra a inserção dos negros como cidadãos, "o Estado se posicionou claramente por uma estratégia racista que projetava o branqueamento da população. Para tal estratégia deveriam concorrer a imigração europeia, de um lado, e a miscigenação, de outro" (Vainer C. B., 1990:114).

o fato é que os negros escravizados foram libertados, mas não alcançaram a liberdade. A mão de obra negra escravizada foi substituída pela mão de obra do imigrante europeu e o lugar que os homens e mulheres negros enfim poderiam assumir na estrutura social brasileira lhes foi negado, o que contrariava as previsões de passagem tranquila do trabalho escravo para o trabalho assalariado em nossas terras. Uma dessas previsões foi a do abolicionista francês M. Quentin que, em 1867, realizou uma comunicação sobre o Brasil na Conferência Contra a Escravidão e afirmou: "O que facilitará singularmente a transição no Brasil é que lá não existe nenhum preconceito de raça [...] lá todos os homens livres são iguais [...]. O liberto ingressa totalmente na vida social, civil e política." (Azevedo C. M. M., 2003:158).

Apesar de ser amplamente divulgado por diversos intelectuais, tal "paraíso racial", de fato, nunca existiu e não é preciso muito esforço para demonstrar isso. Bastaria, por exemplo, observar que "dados de criminalidade apontam que, sujeitos às mesmas penalidades, os negros têm $80 \%$ de chance a mais que os brancos de serem incriminados" (Schwarcz L., 2012:117). Ora, o que se vê é que a posição central dos negros ao longo do processo abolicionista nunca existiu e, pior ainda, os poucos que puderam externar opiniões contrárias ao regime de exclusão vigente ou tiveram suas críticas ignoradas e silenciadas, como é o caso de Gonçalves Dias, ou foram deliberadamente retirados desse campo político de batalha, como no caso do olhar que a crítica teve sobre a obra de Machado de Assis. Com os Racionais Mc's, capitaneados por Mano Brown, no entanto, o espaço será forjado com palavras mais potentes do que um tiro de uma arma de fogo.

\section{Sobreviventes do holocausto urbano}

Na passagem do século XIX para o século xx e já ingressando no XXI, os intelectuais negros no Brasil terão de inventar um espaço para si e inverter o olhar político-cultural dominante associando a categoria social da cor ao elemento classe social. Os Racionais Mc's, dentro dessa lógica, encampam a batalha que Dias e Machado abriram e, em um discurso contundente, na letra da canção Racistas otários, lançada em 1990 no primeiro disco do grupo, Holocausto Urbano, explicam:

Racistas otários nos deixem em paz

Pois as famílias pobres não aguentam mais [...]

os sociólogos preferem ser imparciais

e dizem ser financeiro nosso dilema

mas se analisarmos bem mais você descobre

que negro e branco pobres se parecem mas não são iguais

Articulando cor e classe social, o grupo de rap contrapõe o discurso acadêmico, oficial e central dos sociólogos e demonstram - na mesma chave interpretativa de André Rebouças - que o elemento financeiro é problemático para o estabelecimento sólido dos pobres brasileiros pós-abolição, mas que o elemento racial, que impede a "dimensão coletiva", coloca os sujeitos negros à margem do sistema de modo quase incontornável. Há, todavia, um modo de escapar à marginalização que é ter consciência de que a 
conjuntura social é desfavorável aos negros. Em determinado momento de Racistas otários, por exemplo, ouve-se: "E nossos ancestrais/ Por igualdade lutaram, se rebelaram, morreram/ E hoje, o que fazemos?/ Assistimos a tudo de braços cruzados/ Até parece que nem somos nós os prejudicados".

No fim da canção, uma voz cheia de pompa anuncia: "O Brasil é um país de clima tropical onde as raças se misturam naturalmente e não há preconceito racial". Após essa fala, "ouve-se uma gargalhada sarcástica - um comentário eloquente da visão dos Racionais sobre o mito da democracia racial" (Teperman R., 2015 : 77). Esse mito caindo por terra através da voz dos Racionais vai ser o gatilho para que a juventude negra unase em torno de uma só voz. Pelo menos é isso que na canção Voz ativa, lançada em 1992, os Racionais orientarão:

Mais da metade do país é negra e se esquece

Que tem acesso apenas ao resto que ele oferece [...]

Brancos em cima, negros embaixo, ainda é normal, natural

400 anos depois

1992: tudo igual

Bem-vindos ao Brasil colonial e tal

Precisamos de nós mesmos essa é a questão [...]

Gostarmos de nós, brigarmos por nós

Acreditarmos mais em nós independente do que os outros façam

Tenho orgulho de mim, um rapper em ação

Nós somos negros, sim, de sangue e coração [...]

Justiça é o que nos motiva: a minha, a sua

A nossa voz ativa.

Da postura crítica, porém comprometida com o mecanismo do favor que regia as relações sociais no Brasil Império, de Dias e Machado, passamos à postura comprometida e radical de Mano Brown, Edi Rock, Ice Blue e KL Jay, os quais, fundaram uma nova subjetividade para o ser periférico: "o morador da periferia que assume sua condição, tem orgulho desse lugar e age politicamente a partir dele." (Oliveira A. S., 2018:23). O sujeito lírico de Voz ativa coloca-se como detentor de um saber que precisa chegar à massa de explorados, a fim de que haja a união dos excluídos que, juntos, somam "mais de metade do país", mas, mesmo assim, contentam-se com os "restos". o orgulho desse sujeito encontra-se não só em ser "negro", mas também em estar em "ação" e buscar a justiça para que todos os excluídos também possam deixar de ser marionetes e constituam-se através de uma "voz ativa".

O crítico Acauam Oliveira (2018:24-25) afirmará que a obra dos Racionais passa a ser um marco na música e na cultura nacionais porque "Seu foco está na construção de uma fraternidade de iguais no interior de uma comunidade periférica que se afirma contra um projeto de nação que a deseja exterminar." E que "a aposta dos Racionais [...] [estava] na construção de uma identidade formada a partir da ruptura com essa tradição conciliatória, por meio da afirmação de uma comunidade negra que se desvincula do projeto de nação mestiça concebido até então." Vale dizer, também, que esse projeto de integração racial e mestiçagem vem à tona principalmente pelo fato de que o projeto de embranquecimento da população brasileira, via imigração europeia, fracassou. Nesse sentido:

Podemos dizer que o rap [dos Racionais Mc's] desloca a canção brasileira de um dos seus principais pilares de organização de sentido até então: a identidade nacional pensada em termos de conciliação racial, via mestiçagem, e de classe, via nacionaldesenvolvimento. É como se o gênero tomasse forma a partir dos destroços desse projeto de formação do país, comprometendo-se de modo radical com aqueles que 
ficaram socialmente relegados às margens de um projeto de integração que nunca chegou a se completar.

(Oliveira A. S., 2018:25) seus ouvintes, muito por conta do tom autoritário recorrente em seus primeiros textos. A grande viravolta da obra dos rappers, assumindo uma postura mais agregadora - sem perder a contundência -, será conquistada com o lançamento do álbum Sobrevivendo no inferno, em 1997, que chegou à incrível marca de cerca de 1,5 milhão de cópias vendidas e atingiu praticamente todos os estratos sociais (Oliveira A. S., 2018:21), mesmo com os Racionais praticamente não concedendo entrevistas nem fomentando qualquer tipo de relacionamento com a mídia tradicional. $\mathrm{Na}$ verdade, a conquista do posto de intelectuais revolucionários e periféricos pelos autodenominados quatro pretos mais perigosos do Brasil (Caramante A., 2013) veio da força discursiva de suas letras que entenderam que a "voz ativa" reside também nas contradições e nas incertezas que cercam os que permanecem sobrevivendo no inferno, único espaço a que os negros brasileiros pós-abolição tiveram acesso.

centro cultural. Um centro no qual a identidade periférica e os negros tenham a possibilidade, até então negada, de construir a si mesmos. Não por acaso, em Fórmula mágica da paz, a voz de Mano Brown afirma: "Demorô/ Mas hoje eu posso compreender/ Que malandragem de verdade é viver" (Racionais, 2018:123). Essa conclusão é chave ideológica fundamental para nossa análise, pois implica assumir que a tomada dos espaços sociais pelos negros brasileiros, na visão dos Racionais Mc's, só será possível se os corpos negros permanecerem existindo. Em outras palavras, a maior "malandragem" para os negros é sobreviver pelo fato de que, sendo mais de metade da população brasileira, não haverá a possibilidade de o sistema ignorar sua existência.

de versiculo 3, a estratégia de conscientização dos marginalizados acerca do fato de que a sobrevivência é a melhor forma de tornar-se relevante prossegue. A canção abre com dados acerca da exclusão social e da violência policial a que os negros são submetidos e, em seguida, na primeira parte, Mano Brown afirma-se como "Número um, guia, terrorista da periferia/ Uni-duni-tê, eu tenho pra você/ Um rap venenoso ou uma rajada de PT [...]// A fúria negra ressuscita outra vez/ Racionais, capítulo 4, versículo 3". (Racionais, 2018:50). Como se lê, a ideia de sobrevivência não combina com a ideia de submissão, por isso, o interlocutor, diante da "fúria negra" dos Racionais será atingido por um "rap venenoso", que alterará a visão sobre o conceito de periférico, ou uma "rajada de PT", cuja marca de violência explicita a não aceitação dos mesmos códigos morais e de conduta que vigoraram até então na sociedade brasileira.

A cultura periférica não se encontra mais marginalizada na voz dos Racionais Mc's pelo simples fato de que a arte produzida pelo grupo é menos arte do que arma, como o próprio Mano Brown afirmara: "Não sou artista. Artista faz arte, eu faço arma. sou terrorista." (Oliveira, A. C., 2018:32). A periferia passa a ser o centro de si mesma porque o foco da arte de guerrilha não está mais na escrita que é endereçada para a classe social dominante, como era o caso de Gonçalves Dias e de Machado de Assis, mas, agora, com os Racionais Mc's, o foco é o próprio povo preto e periférico que contraria as estatísticas de exclusão e violência e ufana-se da própria cor e da própria existência:

Mas não...

Permaneço vivo, prossigo a mística

Vinte e sete anos contrariando a estatística 
Seu comercial de TV não me engana

Eu não preciso de status nem fama

Seu carro e sua grana já não me seduz

E nem a sua puta de olhos azuis

Eu sou apenas um rapaz latino-americano

Apoiado por mais de cinquenta mil manos

Efeito colateral que seu sistema fez

Racionais, capítulo 4, versículo 3.

(Racionais, 2018:56)

\section{Considerações finais}

Gonçalves Dias, Machado de Assis e Mano Brown, Edi Rock, Ice Blue e KL Jay, os Racionais Mc's, cada um a seu modo e dentro de seu tempo, foram capazes de, criativamente, alargarem as margens do que se considerava como centro ético-estético na cultura brasileira e, no limite, reinventarem a própria concepção de centro. Todos pretos, esses intelectuais investiram seus esforços em trazer os corpos negros para a discussão sobre os rumos que a sociedade brasileira tomava e toma. No entanto, também cada um a seu modo, esbarraram em dificuldades como o silenciamento, a interpretação preguiçosa por parte dos críticos oficiais e o preconceito de cor e de classe.

O estereótipo, ainda muito vivo na cultura brasileira, do negro malandro não se coaduna à personalidade dos intelectuais que observamos, mas, ainda assim, subjaz ao modo como suas obras foram analisadas pelas instâncias da cultura predominante, já que

[O racismo] era a fórmula preciosa para justificar o domínio branco sobre o resto do mundo: se as outras raças eram biologicamente inferiores, se eram incapazes de atingir os valores mais elevados da civilização, só poderiam sobreviver como as massas trabalhadoras submetidas aos brancos. [...]

A ideologia racista nunca foi uma verificação racional [...]. Por isso, os argumentos puramente racionais parecem insatisfatórios para sua destruição.

(Leite, D. M., 2007 : 38-39)

Seguindo essa linha de análise, talvez a diferença radical entre o modelo crítico adotado pelos Racionais Mc's e por Gonçalves Dias, o “poeta na contramão”, e por Machado de Assis, o "mestre na periferia", resida no papel que a estrutura social e histórica do Brasil do século XIX desempenhava na situação de intelectuais negros e mestiços, principalmente por terem de transitar por espaços sociais autorizados institucionalmente e, por isso mesmo, valerem-se de argumentos mais "puramente racionais", ainda que com nuances. Já no século XX, a mais urgente resolução era a de tomar os espaços sociais e inverter a lógica predominante, a fim de que houvesse sobreviventes do "holocausto urbano" tal qual o fizeram os integrantes do grupo musical Racionais Mc's.

41 A agenda social não poderia mais seguir a lógica "racional” dos racistas - e para nós, ainda não pode -, daí a necessidade entendida, e colocada em prática, pelos Racionais de criar uma lógica de pertencimento para o povo preto e um manual de sobrevivência no inferno da realidade brasileira. 


\section{BIBLIOGRAFIA}

Assis, Machado de, Obra Completa de Machado de Assis, Rio de Janeiro, Edições Jackson, 1937.

Assis, Machado de, Correspondência de Machado de Assis: tomo II, 1870-1889, Sergio P. Rouanet; Org. Irene Moutinho; Sílvia Eleutério. Rio de Janeiro, ABL, Coleção Afrânio Peixoto, 2009.

Assis, Machado de, Obra Completa vol. II, Rio de Janeiro, Nova Aguilar, 1994. Disponível em: http:// machado.mec.gov.br/obra-completa-lista/itemlist/category/25-poesia. Acesso em: 29 de fevereiro de 2020.

Azevedo, Célia M. M, Abolicionismo: Estados Unidos e Brasil, uma história comparada, São Paulo, Annablume, 2003.

Bosi, Alfredo, História concisa da literatura brasileira, 43ª ed., São Paulo, Cultrix, 2006.

Bloom, Harold, Gênio: os 100 autores mais criativos da história da literatura, Traduzido por José Roberto O'Shea, Rio de Janeiro: Objetiva, 2003.

Bruno, Ana Luiza P., A representação da mulher negra em Machado de Assis (Leituras de Mariana e Sabina), Dissertação Letras, Faculdade de Ciências e Letras, UNESP, 2012. Disponível em: http:// wwws.fclar.unesp.br/agenda-pos/estudos_literarios/2642.pdf. Acesso em: 15 de fevereiro de 2020 .

Candido, Antonio, Formação da literatura brasileira, 6ª ed., Belo Horizonte, Itatiaia, 1981.

Caramante, André, “Os quatro pretos mais perigosos do Brasil”. Rolling Stone Brasil, nº 86, 2013. Disponível em: https://rollingstone.uol.com.br/edicao/edicao-86/racionais-mcs-quatro-pretosmais-perigosos-do-brasil/. Acesso em: 28 fev. 2020.

Carvalho, Maria A.R., “André Rebouças e a questão da liberdade”. In: Schwarcz, L. M.; Botelho, A. (dir.). Um enigma chamado Brasil: 29 intérpretes e um país, São Paulo, Companhia das Letras, 2009, p. 46-59.

Denis, Ferdinand, "Resumo da História Literária do Brasil", In: Cesar, Guilhermino, Historiadores e críticos do romantismo. 1. A contribuição europeia: crítica e história literária, São Paulo, EDUSP; Rio de Janeiro, LTC, 1978, p. 35-82.

Dias, Antônio Gonçalves. "Meditação", In: Guanabara, revista mensal, artística, científica e literária, Tomo I, Rio de Janeiro, 1850.

Fitz, Earl E. “A recepção de Machado de Assis e a transformação do romance moderno europeu”, In: Rocha, João Cezar de C. (dir.), Machado de Assis: lido e relido, São Paulo: Editora da Unicamp, 2016, p. 23-40.

Fitz, Earl E., "The reception of Machado de Assis in the United States during the 1950s and 1960s". In: Luso-Brazilian Review, no 46, v. 1, 2009, p. 16-35.

Leite, Dante Moreira, 0 caráter nacional do brasileiro: história de uma ideologia. $7^{\mathfrak{a}}$ ed. rev., São Paulo, Editora UNESP, 2007.

Marques, Wilton J., "Gonçalves Dias, a escravidão e o tapete levantado”, In: Teresa revista de Literatura Brasileira, no 12-13, São Paulo, 2013, p. 469-482.

Marques, Wilton J. Gonçalves Dias: o poeta na contramão (literatura e escravidão no romantismo brasileiro), São Carlos, EdUFSCar, 2010. 
Montello, Josué. Os inimigos de Machado de Assis, Rio de Janeiro, Nova Fronteira, 1998.

Oliveira, Acauam S. de. “O evangelho marginal dos Racionais Mc's”. In: Racionais Mc's. Sobrevivendo no inferno, São Paulo, Companhia das Letras, 2018, p. 19-37.

Racionais Mc's. Sobrevivendo no inferno, São Paulo, Companhia das Letras, 2018.

Racionais Mc's. Escolha seu caminho, Álbum, São Paulo, São Paulo: Zimbabwe, 1992.

Racionais Mc's. Holocausto urbano, Álbum, São Paulo, São Paulo: Zimbabwe, 1990.

Schwarcz, Lilia M., As barbas do imperador: D. Pedro II, um monarca nos trópicos, São Paulo, Companhia das Letras, 1998.

Schwarcz, Lilia M., Nem preto nem branco, muito pelo contrário. Cor e raça na sociabilidade brasileira. São Paulo: Claro Enigma, 2012

Schwarz, Roberto, Um mestre na periferia do capitalismo: Machado de Assis. $4^{a}$ ed., São Paulo, Duas Cidades; Ed. 34, 2000.

Sontag, Susan, “Afterlives: the case of Machado de Assis". In: New Yorker, 7 mai. 1990, p. 102-108.

Teperman, Ricardo, Se liga no som: as transformações do rap no Brasil. São Paulo, Claro Enigma, 2015.

Vainer, Carlos B., "Estado e Raça no Brasil. Notas Exploratórias”. In: Estudos Afro-Asiáticos, nº 18, 1990, p. 103-117.

\section{NOTAS}

1. Seguindo a lição de Wilton J. Marques (2013 : 475), houve atualização da ortografia do texto de Dias, "já quanto à pontuação, entendendo-a como característica inerente à expressividade romântica, esta será preservada tal como se apresenta nos textos".

\section{RESUMOS}

Neste artigo, com base em estudos de psicologia social, antropologia, sociologia e literatura sobre o caráter nacional brasileiro, observamos o papel que a estrutura social e histórica nos séculos XIX e Xx desempenhou na situação de intelectuais negros e mestiços do Brasil. Analisamos como o espaço autorizado institucionalmente influiu na proposição e na avaliação de obras de Gonçalves Dias (1823-1864) e Machado de Assis (1839-1908) e como o grupo Racionais Mc's (1988-) buscou modificar a estrutura estético-social hegemônica vigente até então, através da reorganização do discurso dos sujeitos negros e periféricos brasileiros.

In this paper, based on studies of social psychology, anthropology, sociology, and literature on the Brazilian national character, we observe the role that the social and historical structure in the $19^{\text {th }}$ and $20^{\text {th }}$ centuries played in the situation of black and mestizo intellectuals in Brazil. We analyzed how the institutionally authorized space influenced the proposition and evaluation of works by Gonçalves Dias (1823-1864) and Machado de Assis (1839-1908) and how the Racionais 
Mc's group (1988-) sought to modify the hegemonic aesthetic-social structure until then through the reorganization of the discourse of black and peripheral Brazilian subjects.

Dans cet article, basé sur des études de psychologie sociale, d'anthropologie, de sociologie et de littérature sur le caractère national brésilien, nous observons le rôle que la structure sociale et historique des XIX et XX siècles a joué dans la situation des intellectuels noirs et métis au Brésil. Nous avons analysé comment l'espace institutionnellement autorisé a influencé la proposition et l'évaluation des œuvres de Gonçalves Dias (1823-1864) et Machado de Assis (1839-1908) et comment le groupe Racionais Mc's (1988-) a cherché à modifier la structure hégémonique esthétique-sociale en vigueur jusque-là par la réorganisation du discours des sujets brésiliens noirs et périphériques.

\section{ÍNDICE}

Mots-clés: Gonçalves Dias, Machado de Assis, Racionais Mc's, littérature afro-américaine, identité brésilienne.

Palavras-chave: Gonçalves Dias, Machado de Assis, Racionais Mc's, literatura negra, identidade brasileira.

Keywords: Gonçalves Dias, Machado de Assis, Racionais Mc's, African-American literature, Brazilian identity.

\section{AUTOR}

\section{VALMIR LUIS SALDANHA DA SILVA}

Valmir Luis Saldanha da Silva é doutorando em Estudos Literários pela UNESP (Universidade de São Paulo), é professor de Língua Portuguesa e Literatura no IFSP (Instituto Federal de Ciência e Tecnologia de São Paulo), membro do grupo de estudos LLE (Linguagem, Literatura e Educação) CNPq e pesquisador de literatura italiana, literatura brasileira, inteligência emocional e leitura.Email: professorvalmirluis@gmail.com; valmir.saldanha@ifsp.edu.br 